\title{
Microfracture is more cost-effective than autologous chondrocyte implantation: a review of level 1 and level 2 studies with 5 year follow-up
}

\author{
Tommy Frøseth Aae ${ }^{1,2} \cdot$ Per-Henrik Randsborg ${ }^{3}$ Hilde Lurås ${ }^{4,5}$ • Asbjørn Årøen ${ }^{3,4,6}$. \\ Øystein Bjerkestrand Lian ${ }^{1,7}$
}

Received: 29 September 2017 / Accepted: 8 November 2017 / Published online: 11 November 2017

(C) The Author(s) 2017. This article is an open access publication

\begin{abstract}
Purpose Focal cartilage defects in the knee may have devastating effect on the knee joint, where two of the main surgical treatment options are microfracture and autologous chondrocyte implantation. Comparative studies have failed to establish which method yields the best clinical results. A cost-effectiveness analysis of microfracture and autologous chondrocyte implantation would contribute to the clinical decision process.

Methods A PubMed search identifying level I and level II studies with 5 year follow-up was performed. With the data from these studies, decision trees with associated service provision and costs connected to the two different techniques were designed. In addition to hospital costs, we included costs connected to physiotherapy following surgery. To paint a broader cost picture, we also included indirect costs to the society due to productivity loss caused by work absence.

Results Four high-quality studies, with a follow-up of 5 years, met the inclusion criteria. A total of 319 patients
\end{abstract}

Tommy Frøseth Aae

tommy.aae@gmail.com

Per-Henrik Randsborg

phrandsborg@yahoo.no

Hilde Lurås

hilde.luras@ahus.no

Asbjørn Årøen

asbjorn.aroen@medisin.uio.no

Øystein Bjerkestrand Lian

Oystein.Bjerkestrand.Lian@helse-mr.no

1 Department of Orthopedic Surgery, Kristiansund Hospital, 6518 Kristiansund, Norway

2 Institute of Clinical Medicine, Faculty of Medicine, University of Oslo, Oslo, Norway were included, 170 undergoing microfracture and 149 autologous chondrocyte implantation. The re-operation rate was $23(13.5 \%)$ following microfracture, and 18 (12.1\%) for autologous chondrocyte implantation. Both groups achieved substantially better clinical scores at 5 years compared to baseline. Microfracture was more cost-effective when comparing all clinical scores.

Conclusion Microfracture is associated with both lower costs and lower cost per point increase in patient reported outcome measures. There is a need of well-designed, highquality randomized controlled trials before reliable conclusions regarding cost-effectiveness in the long run is possible. Level of evidence III.

Keywords Microfracture - Autologous chondrocyte implantation · Articular cartilage lesion · Cost-effectiveness

3 Department of Orthopedic Surgery, Akershus University Hospital, 1478 Lørenskog, Norway

4 Institute of Clinical Medicine, University of Oslo, Campus Ahus, 1478 Lørenskog, Norway

5 Department of Health Services Research, Akershus University Hospital, 1478 Lørenskog, Norway

6 Oslo Sports Trauma Research Center (OSTRC), Norwegian School of Sports Sciences, postboks 4014 Ullevål Stadion, 0806 Oslo, Norway

7 Institute of Neuromedicine, Faculty of Medicine, Norwegian University of Science and Technology, 7491 Trondheim, Norway 


$\begin{array}{ll}\text { Abbreviations } \\ \text { ACI } & \text { Autologous chondrocyte implantation } \\ \text { AMIC } & \text { Autologous matrix-induced chondrogenesis } \\ \text { CCI } & \text { Characterized chondrocyte implantation } \\ \text { CPM } & \text { Continuous passive motion } \\ \text { FCD } & \text { Focal cartilage defect } \\ \text { HCA } & \text { Human capital approach } \\ \text { IKDC } & \text { International Knee Documentation Committee } \\ \text { KOOS } & \text { Knee injury and Osteoarthritis Outcome Score } \\ \text { MF } & \text { Microfracture } \\ \text { PROMs } & \text { Patient reported outcome measures }\end{array}$

\section{Introduction}

The articular cartilage in joints is composed of hyaline cartilage, with optimum load bearing and friction properties. Due to limited self-repair ability, an injury to the articular cartilage will lead to permanent damage. Focal cartilage defects (FCDs) of the knee joint may lead to severe morbidity and osteoarthritis [1], and are commonly diagnosed by magnetic resonance imaging or arthroscopy. In a retrospective study of 31,516 knee arthroscopies, Curl et al. found that $63 \%$ had cartilage injuries [2]. Årøen et al. reported that $66 \%$ of 993 knee arthroscopies had cartilage lesions, with $6 \%$ having a full thickness cartilage defect [3].

There are numerous treatment options available, where all aim to reduce pain, restore function, and minimize secondary osteoarthritis. Treatments can broadly be divided into bone-morrow stimulation techniques (microfracture), osteochondral autograft or allograft transplantation and cellbased techniques (autologous chondrocyte implantation) [4, 5]. Microfracture (MF) has gained popularity over the last few decades being a minimal invasive approach with technical simplicity and low costs [6]. In addition, there are no extra laboratory expenses or secondary surgery [7]. The MF technique described by Steadman includes debridement of the defect, before an awl is used to perforate ("microfracture") the subchondral bone [8]. By this method, multipotent mesenchymal stem cells from the condyle are recruited to produce fibrocartilage filling of the defect. In contrast to this procedure, the most advanced cartilage procedure is the autologous chondrocyte implantation (ACI). This is a twostage procedure, where the aim is to produce hyaline-like cartilage filling of the cartilage defect $[9,10]$. First, small samples of normal cartilage tissue are harvested during a simple arthroscopy, and cultured in the laboratory. In the second operation, the cultured chondrocytes are re-implanted into the defect and mature into hyaline-like cartilage.

Short- and long-term studies have reported better function and less pain following knee cartilage surgery than prior to surgery [7,11-13], but normal knee function is normally not achieved [6, 14, 15]. Based on cohort studies with at least 5 years of follow-up, no difference between the various surgical methods in regard to clinical scores, failure rates, and secondary surgeries has been found [16-19]. One study reported that MF and osteochondral autograft transplantation are equally cost-effective treatment options in a 10 year perspective [20]. Previous published studies comparing costs following MF and ACI have not analysed only high evidence studies with a minimum follow-up of 5 years, nor taken into account all the costs related to the procedure. Most notably, the costs of physiotherapy following the procedures are sparse [21, 22], whereas indirect costs to the society related to sick leave are almost absent [23].

Given the increased focus on health care efficiency and the high prevalence of FCDs on the distal femur, one should try to identify the most cost-effective treatment option to contribute to the clinical decision process for these troublesome injuries.

Previous published cost-effectiveness analysis is based on short term follow-up only. The purpose of the current study is to compare costs after 5 years between MF and ACI, based on pre-existing level 1 and level 2 studies.

\section{Materials and methods}

Miller et al. performed a cost-effectiveness analysis of cartilage injuries comparing microfracture and osteochondral autograft transplantation [20]. In the current study, we extent their method by also including costs for physiotherapy and indirect costs to society due to sick leave. A literature search was carried out in January 2017 using the database of PubMed, for clinical trials phase I and II studies comparing MF and ACI for the treatment of FCDs in the distal femur with a minimum 5 years of follow-up. Using the keywords "microfracture", "autologous chondrocyte implantation", "cartilage repair", "cartilage lesions", "mosaicplasty", "osteochondral transfer and transplantation", "osteochondral autograft" and "osteoarticular transfer system", only publications in English were included. Articles with reported evidence level I and II were included. Studies regarding the paediatric and adolescent population were excluded (as these focus on osteochondritis dissecans). As long as they met inclusion criteria, studies comparing other cartilage procedures were included.

According to the standard methods for economic evaluation of health care programs, decision trees following MF and ACI as previously described by Drummond et al. were constructed [24]. Terminal endpoints were either success or failure, where the latter was defined as pain or loss of function which required revision surgery. Based on the decision tree and clinical experience regarding service provision in the two different alternatives, treatment paths were constructed for MF and ACI, respectively. The cost data were taken from a local orthopedic hospital in Norway, and 
verified via personal communication with other orthopedic hospitals in the country. Direct costs including physiotherapy was first calculated, and second indirect costs related to sick leave was included. Hospital costs (unit prices) were based on a cost-per-patient calculation model, which is an established standard for calculating patient-level costs in hospitals [25] (Table 1).

The costs of revision surgery were calculated for the specific procedures (diagnostic arthroscopy, MF, mosaicplasty, ACI, high tibial osteotomy, and total knee arthroplasty), and included costs of a magnetic resonance imaging and a return visit. For the costs of one overnight stay in an orthopedic ward, a Norwegian estimate is $€ 620$ [26]. The length of hospital stays following MF and ACI varies, where stays up to

Table 1 Total cost primary surgery per patient

\begin{tabular}{lcll}
\hline Variable & Unit price $(€)$ & \multicolumn{2}{l}{ Cost (units) } \\
\cline { 3 - 4 } & & MF & ACI \\
\hline Initial consult & 95 & $95(1)$ & $95(1)$ \\
Surgery and material & & 1749 & 3498 \\
Cell culture & 4050 & & 4050 \\
Outpatient follow-up visit & 35 & $70(2)$ & $70(2)$ \\
Hospital stay (each night) & 620 & $620(1)$ & $1860(3)$ \\
Physiotherapy & 30 & $720(24)$ & $1440(48)$ \\
Direct costs & & 3254 & 11,013 \\
Indirect costs (absent from & 215 & $1075(5)$ & $3225(15)$ \\
$\quad$ work) & & & \\
Total costs & & 4329 & 14,238 \\
\hline
\end{tabular}

All costs in Euros $(€)$ per patient

$M F$ microfracture, $A C I$ autologous chondrocyte implantation, $N / A$ not applicable
4 days have been reported [23, 27]. In this study, lengths of stay are set to 1 day for MF and 3 days for ACI which corresponds to both clinical practice and the current literature [28] (Table 2). In regard to revision surgery, we assumed hospital stays of 1 day following diagnostic arthroscopy and mosaicplasty, and 3 days for high tibial osteotomy and total knee arthroplasty.

In regard to postoperative physiotherapy, there is no consensus regarding frequency or duration. Our assumptions are based on clinical experience and personal communications. After ACI, Brittberg recommends physiotherapy twice weekly for 24 weeks (personal communication), while Robert LaPrade at Steadman's clinic recommends physiotherapy twice weekly for 12 weeks following MF (personal communication). When estimating the costs of physiotherapy following revision surgery, we assumed physiotherapy twice weekly for 12 weeks after diagnostic arthroscopy, MF and mosaicplasty, and twice weekly for 24 weeks for ACI, high tibial osteotomy and total knee arthroplasty. The unit cost of one session physiotherapy is $€ 30$ (The Norwegian Physiotherapist Association). No brace was included in the costs.

A human capital approach (HCA) was employed to calculate indirect costs (productivity loss). In HCA, the loss to the society is estimated from the income normally earned by the patients [29]. The idea is that the employees' wages provide an estimate of the value their labour contributes to the economy, and labour that is lost due to sick leave is assumed to reduce the society's total productivity accordingly. A total of 5 days off work is expected following MF surgery, and 15 days following ACI [23]. Based on data from Statistics Norway (2016), a fulltime employee (both genders) aged 30-34 years earns $€ 4667$ per month, or $€ 215$ for each day absent from work [30]. This age range

Table 2 Total cost revision surgery per patient

\begin{tabular}{|c|c|c|c|c|c|c|c|}
\hline \multirow[t]{2}{*}{ Variable } & \multirow[t]{2}{*}{ Unit price $(€)$} & \multicolumn{6}{|c|}{ Cost (units) } \\
\hline & & DA & MF & MOS & ACI & HTO & TKA \\
\hline \multicolumn{8}{|l|}{ Cost revision surgery } \\
\hline Return visit & 95 & 95 (1) & $95(1)$ & $95(1)$ & $95(1)$ & $95(1)$ & $95(1)$ \\
\hline MRI & 198 & $198(1)$ & $198(1)$ & $198(1)$ & $198(1)$ & $198(1)$ & $198(1)$ \\
\hline Revision surgery and material & & 1749 & 1749 & 3098 & 3498 & 8030 & 10,563 \\
\hline Cell culture & 4050 & & & & 4050 & & \\
\hline Outpatient follow up & 35 & $70(2)$ & $70(2)$ & $70(2)$ & $70(2)$ & $70(2)$ & $70(2)$ \\
\hline Hospital stay & 620 & $620(1)$ & $620(1)$ & $620(1)$ & $1860(3)$ & $1860(3)$ & $1860(3)$ \\
\hline Physiotherapy & 30 & $720(24)$ & $720(24)$ & $720(24)$ & $1440(48)$ & $1440(48)$ & $1440(48)$ \\
\hline Direct cost & & 3452 & 3452 & 4801 & 11,211 & 11,693 & 14,226 \\
\hline Indirect cost (absent from work) & 215 & $1075(5)$ & $1075(5)$ & $1075(5)$ & $3225(15)$ & $3225(15)$ & $3225(15)$ \\
\hline Total cost revision surgery & & 4527 & 4527 & 5876 & 14,436 & 14,918 & 17,451 \\
\hline
\end{tabular}

All costs in Euros $(€)$ per patient

$M R I$ magnetic resonance imaging, $D A$ diagnostic arthroscopy, $M F$ microfracture, $A C I$ autologous chondrocyte implantation, $M O S$ mosaicplasty, HTO high tibial osteotomy, TKA total knee arthroplasty 
corresponds to the average age of the patient population. Assessing the indirect costs (sick leave) following revision surgery, we assumed 5 day off work for diagnostic arthroscopy, MF and mosaicplasty, and 15 day off work for ACI, high tibial osteotomy and total knee arthroplasty.

Total costs at 5 years are calculated by summing primary costs and costs for revision surgery.

By comparing total costs and the weighted average of the reported outcome measures, we calculated the costs related to a 1-point increase in each of the reported PROM values following MF and ACI. All costs were converted to 2017 Euros based on the Norwegian consumer price index.

A sensitivity analysis was performed to calculate alternative values to see how sensitive the end result is for the choice of value on different variables. Guidelines often discount costs at a $3 \%$ annual rate, considered to start at 5 years [31]. Since our study has a follow-up of 5 years, the costs were not discounted.

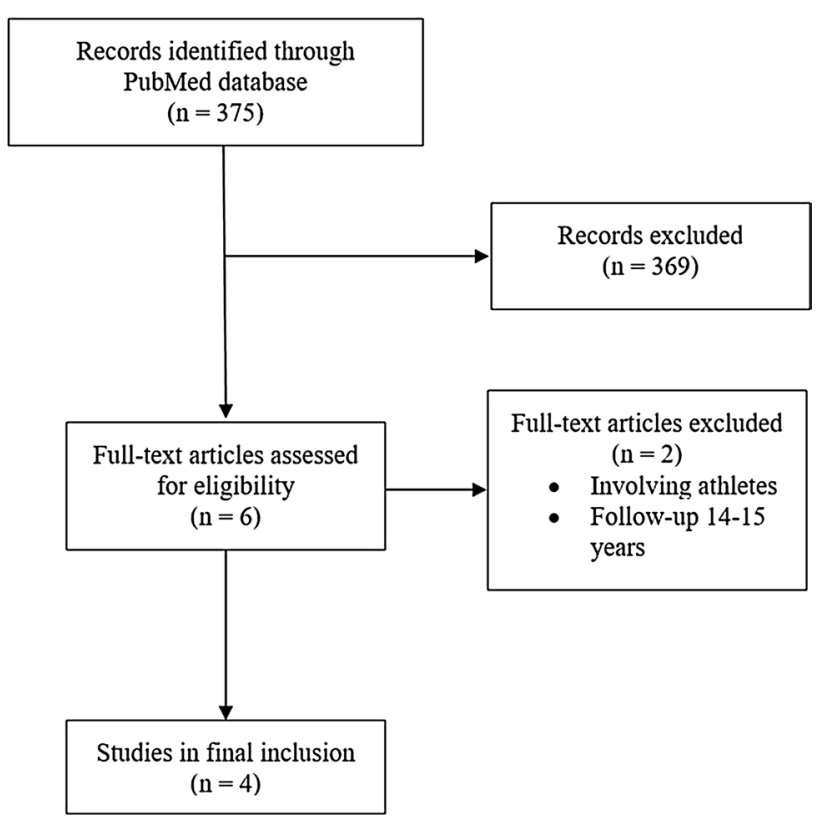

Fig. 1 Flow diagram of article selection included in the study

\section{Results}

Six studies were identified [16-19, 32, 33] (Fig. 1), corresponding to three systematic reviews $[11,34,35]$. Three studies compared MF with ACI using periosteum [16, 18, 32], two compared MF with scaffold ACI [17, 33], whereas one compared MF with characterized chondrocyte implantation (CCI) [19]. One study involving high level athletes did not report failures, and was excluded [33]. One author had published results both after 5 and $14-15$ years [16, 32], but only the 5 year results were included. Hence, 4 articles with 319 patients (208 males, 65\%) formed the basis for comparison of clinical scores schemes, failure rates and revision surgeries [17-19, 32] (Table 3).

170 patients underwent MF, and 149 ACI. Patients in the two groups were $32.1(\mathrm{MF})$ and 33.1 (ACI) years, with lesion sizes $2.5 \mathrm{~cm}^{2}(\mathrm{MF})$ and $3.2 \mathrm{~cm}^{2}(\mathrm{ACI})$. Based on the decision trees, $147(86.5 \%)$ in the MF group, and $131(87.9 \%)$ in the ACI group achieved success at 5 years (Figs. 2, 3).

One study did not specify treatment failure [32]. One study reported re-intervention rates, but did not specify the revision procedure [19]. For our cost analysis, we assumed the non-specific revisions as diagnostic arthroscopies (ten in the MF group and seven in the ACI group).

MF had direct costs of $€ 3254$ at baseline (Table 1), rising to $€ 3892$ at 5 years (Table 4), while ACI was $€ 11,013$ at baseline, increasing to $€ 11,558$ at 5 years. When we included productivity loss due to sick leave, MF had total initial costs of $€ 4329$ rising to $€ 5150$ at 5 years. For ACI, the total costs at baseline and at 5 years were $€ 14,238$ and $€ 14,941$, respectively. Total costs connected to revision surgery were slightly higher in the MF group (€821) compared to ACI (€703) (Table 4).

Different validated patient reported outcome measures (PROMs) were used. The Tegner score was used in three studies [17, 18, 32], the Lysholm score was reported in two $[18,32]$, whereas the visual analogue scale (VAS) [32], Short Form 36 (SF-36) [32], Hospital for Special Surgery (HSS) [18], the Knee Injury and Osteoarthritis Outcome Score (KOOS) [19] and the International Knee Documentation Committee (IKDC) [17] were reported in one study each. Comparing the weighted average of the preoperative
Table 3 Summary of the included articles

\begin{tabular}{lllll}
\hline Level & References & Technique & Patients & PROMs \\
\hline I & Knutsen et al. [32] & MF-P-ACI & $40-40$ & VAS, Lysholm, Tegner, SF-36 \\
II & Lim et al. [18] & MF-P-ACI & $29-18$ & Lyshom, Tegner, HSS Knee score \\
II & Kon et al. [17] & MF-scaffold ACI & $40-40$ & IKDC, Tegner \\
I & Vanlauwe et al. [19] & MF-CCI & $61-51$ & KOOS \\
\hline
\end{tabular}

$M F$ microfracture, $P$-ACI autologous chondrocyte implantation using periosteum, PROMs patient reported outcome measures, VAS visual analogoue scale, SF-36 short form 36, HSS hospital for special surgery, KOOS Knee Injury and Osteoarthritis Outcome Score, IKDC International Knee Documentation Committee, Ref reference number 


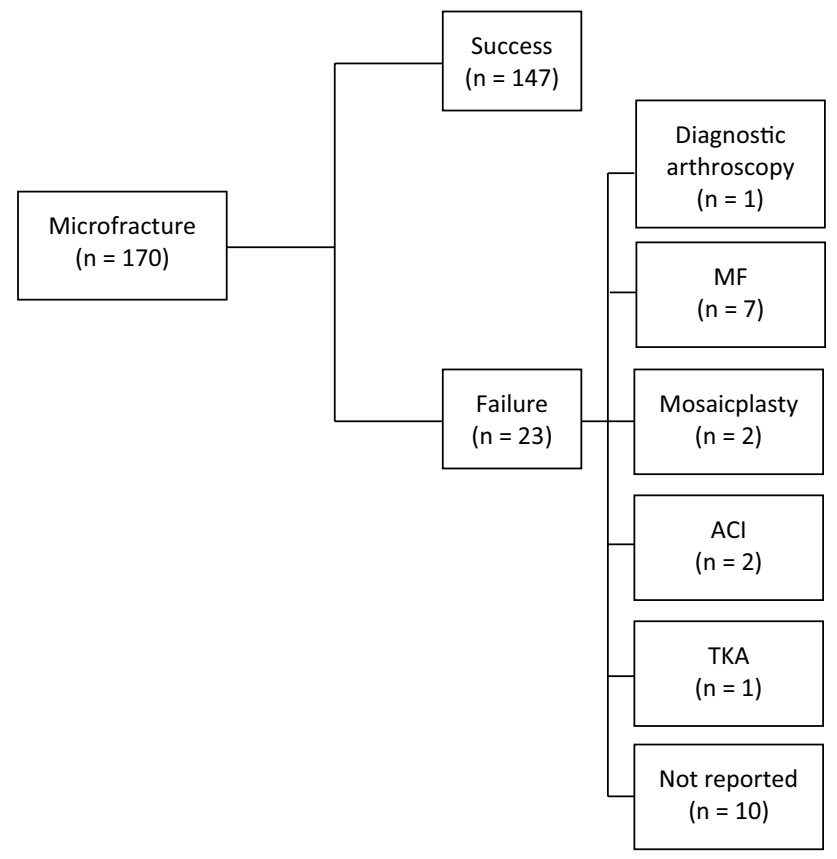

Fig. 2 Microfracture decision tree. $n$ number of patients, $M F$ microfracture, $A C I$ autologous chondrocyte implantation, $T K A$ total knee arthroplasty

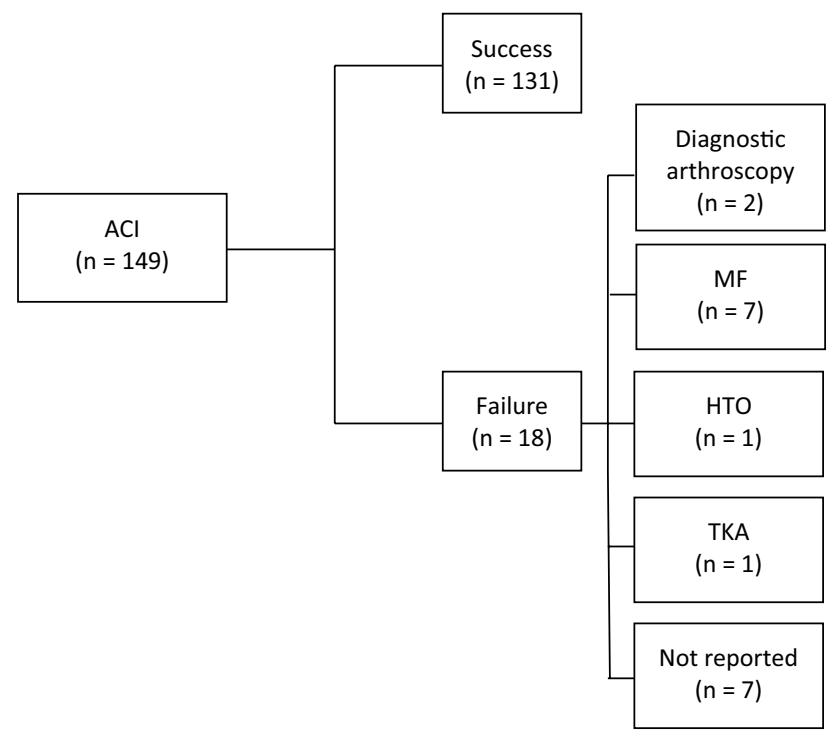

Fig. 3 Autologous chondrocyte implantation decision tree. $n$ number of patients, $M F$ microfracture, HTO high tibial osteotomy, TKA total knee arthroplasty

PROMs with the weighted average of the PROMs after 5 years, all reported statistically clinical improvement for both MF and ACI [34, 36]. Based on the weighted average of the PROMs, a comparative cost-effectiveness analysis was carried out given a 1-point increase on each of the reported clinical scores for total costs at 5 years. For all measures, a 1-point increase in clinical scores had lower costs for MF than for ACI at 5 years (Table 5).

The sensitivity analysis showed that a $66 \%$ reduction in the total costs following ACI or a $190 \%$ increase in the total costs of MF led to equivalent total costs at 5 years. Comparing only primary direct costs, a reduction in costs of 70\% after ACI, or a $239 \%$ increase in costs after MF would lead to equivalent costs at baseline. Assuming identical costs for hospital stay, physiotherapy and sick leave after the primary surgery, an increase in costs of $69 \%$ following MF and a decrease in costs of $41 \%$ after ACI would lead to identical total costs after the primary surgery.

\section{Discussion}

The most important finding of the present study was that MF is more cost-effective than ACI for the treatment of FCDs in the distal femur with 5 year follow-up. The main difference in total costs is related to the primary surgery, where MF is less expensive than ACI. Costs following revision surgery are however lower in the ACI group, respectively, $€ 703$ (ACI) and $€ 821$ (MF) per patient.

The included studies have demonstrated that the clinical scores are statistically significantly better at 5 years compared to pre-surgery for both methods. Not all studies reported variances or standard deviations, so we were unable to calculate a precise $p$ value that demonstrates that the difference in cost-effectiveness is statistically significant. However, given the large differences in costs per point improvement between MF and ACI, it is unlikely that our findings are purely coincidental.

In a recent study comparing MF, osteochondral autograft transplantation and ACI, Schrock et al. reported that MF was the most cost-effective treatment option for chondral lesions in the knee, confirming our findings [37]. In contrast, Mistry et al. reported ACI to be cost-effective compared to MF [22]. When calculating costs, Mistry et al. assumed ACI to be performed as outpatient surgery with a total of six outpatient follow-ups, while MF was assumed to be inpatient surgery. Because ACI is a far more invasive procedure than MF, we assumed 3 days of hospitalization and two outpatient follow-ups after ACI, and 1 day of hospitalization following MF. This is the most important reason why our results differ to Mistry et al. In addition, our study adds costs related to sick leave.

There is a wide variation between surgeons in relation with indication for surgery, preferred surgical technique, postoperative physiotherapy, and outcome assessment [38]. Some have suggested that MF should be performed as first procedure in FCDs on the femur due to the simplicity of the procedure and the associated low costs $[6,7,39]$. MF has, 
Table 4 Total costs at 5 years

\begin{tabular}{|c|c|c|c|}
\hline & & MF (patients) & ACI (patients) \\
\hline \multicolumn{4}{|l|}{ Direct costs } \\
\hline Primary surgery & & $553,180(170)$ & $1,640,937(149)$ \\
\hline \multicolumn{4}{|l|}{ Revision surgery } \\
\hline & Unit price $(€)$ & & \\
\hline DA & 3452 & $3452(1)$ & $6904(2)$ \\
\hline MF & 3452 & $24,164(7)$ & $24,164(7)$ \\
\hline MOS & 4801 & $9602(2)$ & N/A \\
\hline ACI & 11,211 & $22,422(2)$ & N/A \\
\hline HTO & 11,693 & N/A & $11,693(1)$ \\
\hline TKA & 14,226 & $14,226(1)$ & $14,226(1)$ \\
\hline Not reported & 3452 & $34,520(10)$ & $24,164(7)$ \\
\hline Direct costs & & $661,566(170)$ & $1,722,088(149)$ \\
\hline Direct costs per patient & & 3892 & 11,588 \\
\hline \multicolumn{4}{|l|}{ Total costs } \\
\hline Primary surgery & & $735,930(170)$ & $2,121,462(149)$ \\
\hline \multicolumn{4}{|l|}{ Revision surgery } \\
\hline & Unit price $(€)$ & & \\
\hline DA & 4527 & $4,527(1)$ & $9054(2)$ \\
\hline MF & 4527 & $31,689(7)$ & $31,689(7)$ \\
\hline MOS & 5876 & $11,752(2)$ & N/A \\
\hline ACI & 14,436 & $28,872(2)$ & N/A \\
\hline HTO & 14,918 & N/A & $14,918(1)$ \\
\hline TKA & 17,451 & $17,451(1)$ & $17,451(1)$ \\
\hline Not reported & 4527 & $45,270(10)$ & $31,689(7)$ \\
\hline Total costs revision surgery & & $139,561(170)$ & $104,801(149)$ \\
\hline Revision surgery costs per patient & & $821(23)$ & $703(18)$ \\
\hline Total costs & & $875,491(170)$ & $2,226,263(149)$ \\
\hline Total costs per patient & & 5150 & 14,941 \\
\hline
\end{tabular}

The non-specific revisions listed as not reported were assumed as diagnostic arthroscopy in the cost analysis. The cost calculations after primary surgery is based on Table 1

All costs in Euros (€)

$D A$ diagnostic arthroscopy, $M F$ microfracture, MOS mosaicplasty, ACI autologous chondrocyte implantation, $H T O$ high tibial osteotomy, $T K A$ total knee arthroplasty, N/A not applicable

therefore, become the gold standard to which other methods have been compared in clinical trials [27, 40].

The effect of the cartilage lesion size on symptoms is poorly investigated. Some authors recommend ACI for cartilage lesions larger than $4 \mathrm{~cm}^{2}[7,41]$, but the literature is unclear on lesions ranging from 2 to $4 \mathrm{~cm}^{2}$ [42]. The average lesion sizes in our study were slightly different between the groups $\left(2.5 \mathrm{~cm}^{2}\right.$ for $\mathrm{MF}$ and $3.2 \mathrm{~cm}^{2}$ for $\left.\mathrm{ACI}\right)$, which probably do not affect our result. Recent research on anterior cruciate ligament reconstruction in combination with articular cartilage injury has found the effect of the lesion size to be minor [43].

Kon et al. compared MF with scaffold ACI and found a small clinical benefit in favour of ACI after 5 years [17]. Knutsen et al. reported no clinical significant differences comparing MF and ACI after 14-15 years [16]. Radiological early signs of osteoarthritis were found in $48 \%$ in the MF group and $57 \%$ in the ACI group. In a long-term perspective, this could affect the cost-effectiveness of these two methods.

There are technological advances both within MF and ACI. Nanofracture, scaffolds, and autologous matrixinduced chondrogenesis are gaining popularity, and may give a different clinical and cost picture of microfracture derived procedures. Scaffold may induce significantly higher costs when comparing MF with other cartilage procedures. Published papers on ACI are mainly based on first generation procedures, but second and third generation ACI have now been implemented both in clinical trials and practice. However, long-term results are not yet available [44]. Besides, the use of characterized chondrocytes implantation may yield different results than ACI. A third factor is that ACI is performed as a two-stage procedure. The development of 
Table 5 Cost per 1-point improvement in the patient reported outcome measures for total cost at 5 years

\begin{tabular}{|c|c|c|}
\hline PROM & $\begin{array}{l}\text { PROM difference } \\
\text { Baseline-5 years }\end{array}$ & $\begin{array}{l}\text { Costs per point } \\
\text { Improvement } \\
\text { per patient }(€)\end{array}$ \\
\hline \multicolumn{3}{|l|}{ VAS } \\
\hline MF & 29 & 178 \\
\hline $\mathrm{ACI}$ & 28 & 534 \\
\hline \multicolumn{3}{|c|}{ Lysholm } \\
\hline MF & 26 & 198 \\
\hline ACI & 19 & 786 \\
\hline \multicolumn{3}{|l|}{ Tegner } \\
\hline MF & 1.8 & 2861 \\
\hline ACI & 2.8 & 5336 \\
\hline \multicolumn{3}{|l|}{ SF-36 } \\
\hline MF & 10 & 515 \\
\hline ACI & 7 & 2134 \\
\hline \multicolumn{3}{|l|}{ HSS } \\
\hline MF & 9.4 & 548 \\
\hline ACI & 10.0 & 1494 \\
\hline \multicolumn{3}{|l|}{ KOOS } \\
\hline MF & 14.1 & 365 \\
\hline $\mathrm{ACI}$ & 21.2 & 705 \\
\hline \multicolumn{3}{|l|}{ IKDC } \\
\hline MF & 30 & 172 \\
\hline $\mathrm{ACI}$ & 42 & 356 \\
\hline
\end{tabular}

All costs in Euros $(€)$

PROM patient reported outcome measure, $M F$ microfracture, $A C I$ autologous chondrocyte implantation, $V A S$ visual analogue scale, $S F-36$ short form 36, HSS hospital for special surgery, KOOS Knee Injury and Osteoarthritis Outcome Score, IKDC International Knee Documentation Committee

one-stage procedures may yield different health economic effects than traditional ACI, and would probably lower the costs substantially [23].

This study has limitations. Studies with evidence levels 1 and 2 comparing MF and ACI with a minimum follow-up at 5 years are few, leading to relatively small study populations. This may lead to bias and affect the results published in this article. Yet, to this date, these are the only high-quality studies with 5 year follow-up.

Another limitation is the fact that the MF group had slightly smaller lesions and, therefore, might represent patients which are more responsive to physiotherapy after surgery. Supervised physiotherapy has also been shown to be effective together with debridement of the lesion [45], and our study cannot determine which method yield better clinical results.

Knutsen et al. published the SF-36 and Tegner score only for the success patients, and not for the failures [32]. This may lead to an overestimation of these scores, as we must assume that failures would have lower scores than the successes.

Physiotherapy before surgery and costs related to independent training are not included in our calculations because we assume them to be similar for the two groups. A wide range of postoperative physiotherapy protocols after MF and ACI exists. Some permit weight-bearing, while others use continuous passive motion (CPM) [13, 45-48]. These differences may affect the cost calculations.

Ten patients in the MF group and seven in the ACI group were re-operated, and the procedure was assumed to be diagnostic arthroscopies. If we assumed another reoperation procedure, this would affect the cost estimates. When estimating the costs related to hospital stay, work absence, and physiotherapy after revision surgery, we used the cost estimates from primary surgery, which may be an underestimation.

In regard to capital costs, account investments and orthopedic skills were not taken into account, i.e., we have assumed that hospitals can switch between MF and ACI, which in practice is not the case.

The unit prices employed in our calculations is extracted from a local orthopedic hospital, and confirmed with other orthopedic hospitals in Norway, which may limit the transferability of the study. An international cost analysis is difficult to perform because different countries face different institutional and financial constraints, including different unit prices. On the other hand, their assumption regarding service provision related to surgery, postoperative physiotherapy and sick leave are comparable to other studies, thereby giving a certain degree of transferability globally [22, 23, 37].

The results are based on 5 year follow-up. In light of cartilage pathologies, this may be sparse. However, failures usually occur within 2-3 years after the initial surgery [49, 50], so our timeline seems sufficient to capture failures. Furthermore, none of the included studies compared surgical treatment with conservatively treatment, so the true effect of surgery is in fact not known [35, 51]. High-quality studies with follow-up exceeding 5-10 years with a conservative control group are needed to be able to draw conclusions on this painful and morbid disease. Treatment of FCDs is expensive for the society, and our study may contribute to the decision process in clinical practice. This study has a broader perspective than previous cost analyses and should be of particular interest for orthopedic surgeons of this particular knee injury.

\section{Conclusion}

There is evidence for the benefits of cartilage repair surgery using MF and ACI based on the 5 year results published 
when evaluating health costs related to the procedures. The MF procedure is more cost-effective than ACI based on published 5 year results, but there is a need of well-designed, high-quality randomized controlled trials with long-term results before safe conclusions can be made.

Acknowledgements We thank Gunnar Knutsen for providing us with data from his published studies, Heidi Andreassen Hanvold for physiotherapy advice when calculating these costs, Tor Åge Myklebust and Turid Follestad for statistical advice and Myrthle Hoel for secretarial support.

Author contributions TFA performed literature search, drafted and edited the article. PHR co-drafted and co-edited the article. HL codrafted and co-edited the health economic method, results and discussion. OBL gave critical review of the manuscript. AA launched the hypothesis of the study with study design and gave critical review of the manuscript and provided funding. All authors made contributions to design, was involved in the drafting and read and approved the final manuscript.

\section{Compliance with ethical standards}

Conflict of interest The authors declare that they have no competing interests.

Funding Funded by research grants from the Norwegian Research Council, awarded the Norwegian Cartilage Project (NCP), Grant No. 2015107.

Ethical approval The manuscript uses clinical data based on previous published literature, all approved by an ethics committee. This study is in accordance with the ethical standards of the 1964 Declaration of Helsinki.

Open Access This article is distributed under the terms of the Creative Commons Attribution 4.0 International License (http://creativecommons.org/licenses/by/4.0/), which permits unrestricted use, distribution, and reproduction in any medium, provided you give appropriate credit to the original author(s) and the source, provide a link to the Creative Commons license, and indicate if changes were made.

\section{References}

1. Heir S, Nerhus TK, Røtterud JH, Løken S, Ekeland A, Engebretsen L, Arøen A (2010) Focal cartilage defects in the knee impair quality of life as much as severe osteoarthritis: a comparison of knee injury and osteoarthritis outcome score in 4 patient categories scheduled for knee surgery. Am J Sports Med 38:231-237

2. Curl WW, Krome J, Gordon ES, Rushing J, Smith BP, Poehling GG (1997) Cartilage injuries: a review of 31,516 knee arthroscopies. Arthroscopy 13:456-460

3. Arøen A, Løken S, Heir S, Alvik E, Ekeland A, Granlund O, Engebretsen L (2004) Articular cartilage lesions in 993 consecutive knee arthroscopies. Am J Sports Med 32:211-215

4. Farr J, Cole B, Dhawan A, Kercher J, Sherman S (2011) Clinical cartilage restoration: evolution and overview. Clin Orthop Relat Res 469:2696-2705
5. Ozmeric A, Alemdaroglu KB, Aydogan NH (2014) Treatment for cartilage injuries of the knee with a new treatment algorithm. World J Orthop 14:677-684

6. Bekkers JE, Inklaar M, Saris DB (2009) Treatment selection in articular cartilage lesions of the knee: a systematic review. Am J Sports Med 2009(Suppl 1):148S-155S

7. Mithoefer K, McAdams T, Williams RJ, Kreuz PC, Mandelbaum BR (2009) Clinical efficacy of the microfracture technique for articular cartilage repair in the knee: an evidence-based systematic analysis. Am J Sports Med 37:2053-2063

8. Steadman JR, Rodkey WG SS, Briggs K (1997) Microfracture technique for full-thickness chondral defects: technique and clinical results. Oper Tech Orthop 7:300-304

9. Brittberg M, Lindahl A, Nilsson A, Ohlsson C, Isaksson O, Peterson L (1994) Treatment of deep cartilage defects in the knee with autologous chondrocyte transplantation. N Engl J Med 33:889-895

10. Gomoll AH, Farr J, Gillogly SD, Kercher J, Minas T (2010) Surgical management of articular cartilage defects of the knee. J Bone Jt Surg Am 92:2470-2490

11. Goyal D, Keyhani S, Lee EH, Hui JH (2013) Evidence-based status of microfracture technique: a systematic review of level I and II studies. Arthroscopy 29:1579-1588

12. Safran MR, Seiber K (2010) The evidence for surgical repair of articular cartilage in the knee. J Am Acad Orthop Surg $18: 259-266$

13. Steadman JR, Briggs KK, Rodrigo JJ, Kocher MS, Gill TJ, Rodkey WG (2003) Outcomes of microfracture for traumatic chondral defects of the knee: average 11-year follow-up. Arthroscopy 19:477-484

14. Loken S, Heir S, Holme I, Engebretsen L, Aroen A (2010) 6-year follow-up of 84 patients with cartilage defects in the knee. Knee scores improved but recovery was incomplete. Acta Orthop 81:611-618

15. Solheim E, Hegna J, Inderhaug E, Øyen J, Harlem T, Strand T (2016) Results at 10-14 years after microfracture treatment of articular cartilage defects in the knee. Knee Surg Sports Traumatol Arthrosc 24:1587-1593

16. Knutsen G, Drogset JO, Engebretsen L, Grøntvedt T, Ludvigsen TC, Løken S, Solheim E, Strand T, Johansen O (2016) A randomized multicenter trial comparing autologous chondrocyte implantation with microfracture: long-term follow-up at 14 to 15 years. J Bone Jt Surg Am 98:1332-1339

17. Kon E, Gobbi A, Filardo G, Delcogliano M, Zaffagnini S, Marcacci M (2009) Arthroscopic second-generation autologous chondrocyte implantation compared with microfracture for chondral lesions of the knee: prospective nonrandomized study at 5 years. Am J Sports Med 37:33-41

18. Lim HC, Bae JH, Song SH, Park YE, Kim SJ (2012) Current treatments of isolated articular cartilage lesions of the knee achieve similar outcomes. Clin Orthop Relat Res 470:2261-2267

19. Vanlauwe J, Saris DB, Victor J, Almqvist KF, Bellemans J, Luyten FP (2011) Five-year outcome of characterized chondrocyte implantation versus microfracture for symptomatic cartilage defects of the knee: early treatment matters. Am J Sports Med 39:2566-2574

20. Miller J, Ssmith MV, Matava MJ, Wright RW, Brophy RH (2015) Microfracture and osteochondral autograft transplantation are cost-effective treatments for articular cartilage lesions of the distal femur. Am J Sports Med 43:2175-2181

21. Elvidge J, Bullement A, Hatswell AJ (2016) Cost effectiveness of characterised chondrocyte implantation for treatment of cartilage defects of the knee in the UK. Pharmacoeconomics 34:1145-1159

22. Mistry H, Connock M, Pink J, Shyangdan D, Clar C, Royle P, Court R, Biant LC, Metcalfe A, Waugh N (2017) Autologous 
chondrocyte implantation in the knee: systematic review and economic evaluation. Health Technol Assess 21:1-294

23. de Windt TS, Sorel JC, Vonk LA, Kip MM, Ijzerman MJ, Saris DB (2016) Early health economic modelling of single-stage cartilage repair. Guiding implementation of technologies in regenerative medicine. J Tissue Eng Regen Med. https://doi.org/10.1002/ term. 2197

24. Drummond M, Schulpher MJ, Claxton K, Stodart GL, Torrance GW (2015) Methods for the economic evaluation of health care programmes. Oxford University Press, Oxford

25. The Norwegian Health Directorate (2012) National specification for CPP modeling 2012 - concepts and methods. https://helsedirektoratet.no/Lists/Publikasjoner/Attachments/673/Nasjonalspesifikasjon-for-KPP-modellering-2012-IS-2033.pdf. Accessed 24 May 2017

26. Stien R (2001) Slice price - an attempt to improve financial management in Norwegian hospitals. Tidsskr Nor Legeforen 9:1132

27. Knutsen G, Engebretsen L, Ludvigsen TC, Drogset JO, Grøntvedt T, Solheim E, Strand T, Roberts S, Isaksen V, Johansen O (2004) Autologous chondrocyte implantation compared with microfracture in the knee. A randomized trial. J Bone Jt Surg Am 86(A):455-464

28. Van Assche D, Van Caspel D, Staes F, Saris DB, Bellemans J, Vanlauwe J, Luyten FP (2011) Implementing one standardized rehabilitation protocol following autologous chondrocyte implantation or microfracture in the knee results in comparable physical therapy management. Physiother Theory Pract 27:125-136

29. Berger ML, Murray JF, Xu J, Pauly M (2001) Alternative valuations of work loss and productivity. J Occup Environ Med 43:18-24

30. Statistics Norway. Salary, all employees 2016. https://www.ssb. no/lonnansatt. Accessed 24 May 2017

31. Drummond M, Manca A, Sculpher M (2005) Increasing the generalizability of economic evaluations: recommendations for the design, analysis, and reporting of studies. Int J Technol Assess Health Care 21:165-171

32. Knutsen G, Drogset JO, Engebretsen L, Grøntvedt T, Isaksen V, Ludvigsen TC, Roberts S, Solheim E, Strand T, Johansen O (2007) A randomized trial comparing autologous chondrocyte implantation with microfracture. Findings at five years. J Bone Jt Surg Am 89:2105-2112

33. Kon E, Filardo G, Berruto M, Benazzo F, Zanon G, Della Villa S, Marcacci M (2011) Articular cartilage treatment in high-level male soccer players: a prospective comparative study of arthroscopic second-generation autologous chondrocyte implantation versus microfracture. Am J Sports Med 39:2547-2557

34. Kraeutler MJ, Belk JW, Purcell JM, McCarty EC (2017) Microfracture versus autologous chondrocyte implantation for articular cartilage lesions in the knee: a systematic review of 5-year outcomes. Am J Sports Med. https://doi. org/10.1177/0363546517701912

35. Magnussen RA, Dunn WR, Carey JL, Spindler KP (2008) Treatment of focal articular cartilage defects in the knee. Clin Orthop Relat Res 466:952-962

36. Oussedik S, Tsitskaris K, Parker D (2015) Treatment of articular cartilage lesions of the knee by microfracture or autologous chondrocyte implantation: a systematic review. Arthroscopy 31:732-744

37. Schrock JB, Kraeutler MJ, Houck DA, McQueen MB, McCarty EC (2017) A cost-effectiveness analysis of surgical treatment modalities for chondral lesions of the knee: microfracture, osteochondral autograft transplantation, and autologous chondrocyte implantation. Orthop J Sports Med 5:2325967117704634
38. Theodoropoulos J, Dwyer T, Whelan D (2012) Microfracture for knee chondral defects: a survery of surgical pratice among Canadian orthopedic surgeons. Knee Surg Sports Traumatol Arthrosc 20:2430-2437

39. Gill TJ, Asnis PD, Berkson EM (2006) The treatment of articular cartilage defects using the microfracture technique. J Orthop Sports Phys Ther 36:728-738

40. Saris DB, Vanlauwe J, Victor J, Haspl M, Bohnsack M, Fortems Y, Vandekerckhove B, Almqvist KF, Claes T, Handelberg F, Lagae K, van der Bauwhede J, Vandenneucker H, Yang KG, Jelic M, Verdonk R, Veulemans N, Bellemans J, Luyten FP (2008) Characterized chondrocyte implantation results in better structural repair when treating symptomatic cartilage defects of the knee in a randomized controlled trial versus microfracture. Am J Sports Med 36:235-246

41. Basad E, Ishaque B, Bachmann G, Stürz H, Steinmeyer J (2010) Matrix-induced autologous chondrocyte implantation versusmicrofracture in the treatment of cartilage defects of the knee: a 2-year randomised study. Knee Surg Sports Traumatol Arthrosc 18:519-527

42. Sommerfeldt MF, Magnussen RA, Hewett TE, Kaeding CC, Flanigan DC (2016) Microfracture of articular cartilage. JBJS Rev 28:e6

43. Røtterud JH, Sivertsen EA, Forssblad ML, Engebretsen L, Aroen A (2015) Effect on patient-reported outcome of debridement or microfracture of concomitant full-thickness cartilage lesions in anterior cruciate ligament-reconstructed knees. Orthop J Sports Med 3:2325967115S2325900094

44. Fu F, Soni A (2016) ACI versus microfracture: the debate continues. J Bone Jt Surg Am 98:e69 (61-62)

45. Wondrasch B, Arøen A, Røtterud JH, Høysveen T, Bølstad K, Risberg MA (2013) The feasibility of a 3-month active rehabilitation program for patients with knee full-thickness articular cartilage lesions: the Oslo Cartilage Active Rehabilitation and Education Study. J Orthop Sports Phys Ther 43:310-324

46. Edwards PK, Ackland T, Ebert JR (2014) Clinical rehabilitation guidelines for matrix-induced autologous chondrocyte implantation on the tibiofemoral joint. J Orthop Sports Phys Ther 44:102-119

47. Karnes JM, Harris JD, Griesser MJ, Flanigan DC (2013) Continuous passive motion following cartilage surgery: does a common protocol exist? Phys Sportsmed 41:53-63

48. Marder RA, Hopkins G Jr, Timmerman LA (2005) Arthroscopic microfracture of chondral defects of the knee: a comparison of two postoperative treatments. Arthroscopy 21:152-158

49. Gudas R, Gudaite A, Pocius A, Gudiene A, Cekanauskas E, Monastyreckiene E, Basevicius A (2012) Ten-year follow-up of a prospective, randomized clinical study of mosaic osteochondral autologous transplantation versus microfracture for the treatment of osteochondral defects in the knee joint of athletes. Am J Sports Med 40:2499-2508

50. Harris JD, Siston RA, Brophy RH, Lattermann C, Carey JL, Flanigan DC (2011) Failures, reoperations, and complications after autologous chondrocyte implantation - a systematic review. Osteoarthr Cartil 19:779-791

51. Aae TF, Randsborg PH, Breen AB, Visnes H, Vindfeld S, Sivertsen EA, Løken S, Brinchmann J, Hanvold HA, Årøen A (2016) Norwegican Cartilage Project—a study protocol for a doubleblinded randomized controlled trial comparing arthroscopic microfracture with arthroscopic debridement in focal cartilage defects in the knee. BMC Musculoskelet Disord 17:292 